\title{
Managing Diversity: Afghan-Americans And The Aftermath Of The Twin Towers Tragedy
}

Dr. Belal A. Kaifi, Franklin University, USA Wajma Aslami, Saint Mary’s College, USA

\begin{abstract}
Ethnic and religious diversity is part of each society in the modern world and being an Afghan is another dimension of these differences in the United States. The research question for this study was to see if Afghan-Americans are experiencing more discriminatory practices as a result of the 9/11 events. The results of 502 Afghan-Americans demonstrated that they do report more discrimination in the post-9/11 era. Specifically, Afghan men have experienced more discrimination in the workplace and Afghan women have experienced more discrimination in public. Implications and recommendations are offered for effective diversity management.
\end{abstract}

Keywords: Afghan-Americans, Afghanistan, 9/11, discrimination, USA, leadership

\section{INTRODUCTION}

$\mathrm{n}$ the years after September 11, 2001, there have been many reported incidents of discrimination, hostility, and even extreme violence towards Muslims and people who look Muslim. "Nearly three out of four Muslims knew someone who had experienced religious prejudice since 9/11 or had suffered abuse themselves. Many American Muslims have doubts about whether they are accepted as real Americans" (Barrett, 2006, p. 6). Findley (2001) reports, "In recent years, mosques were the target of arsonist in Yuba City, California, Springfield, Illinois, Greenville, South Carolina, and Minneapolis, and vandalism has occurred at mosques in Michigan, Indiana, Massachusetts, New Jersey, and Georgia" (p. 61). Muslims have dealt with arson, intimidation, and the media spreading inaccurate reports about Islam. According to Barrett (2006), "the arrest and detention of twelve hundred Muslim and Arab men in late 2001 and the subsequent interrogation of eight thousand more, have played an even larger role in making many Muslims feel insecure and unwelcome" (p. 5). As a result, many Muslims have altered their identities to blend in with the general public (Kaifi, 2009). Kearney (2003) reports, "The initial response of President Bush was to divide the world into good and evil. In the days immediately following the terror, he declared a 'crusade' against the evil scourge of terrorism" (p. 24).

Tatum (1997) explains "Although conversations about race, racism, and racial identity tend to focus on Black-White relations, to do so ignores the experiences of other targeted racial or ethnic groups" (p. 131). Wagner (2004) exclaims, "Suddenly, average Americans were talking about Osama Bin Laden, jihad, Muslim extremism, the Taliban, and so forth. New words and new ideas were now forming the basis of coffee table discussion" (p. 20). It is a fact that people in the West and in the Muslim world need to learn more about each other. As Abdo (2006) explains, "much of the hostility toward Muslims reflects the lack of knowledge about Islam that has persisted since the first Muslims arrived in America more than three hundred years ago" (p. 7). Ramadan (2004) explains the pervasiveness of the problem: "Prejudices, racism, and Islamophobia are tangible expressions of the hard reality of Western societies, and Muslims must not naively think that these will simply disappear as they become citizens settled in their societies" (p. 226). This study focuses on the impact of 9/11 on Afghan-Americans who came to America for freedom, opportunity, and equality. 


\section{POST-9/11 LITERATURE}

Livengood and Stodolska (2004) conducted a study that allowed them to interview American Muslims in the United States post-September 11, 2001. According to Livengood and Stodolska (2004), "The events of the September 11, 2001 had a profound effect on average 'mainstream' Americans and also on many members of ethnic groups that call America their home" (p. 183). The authors further state, "Since all 19 hijackers were identified as Muslims, anger of many Americans turned against members of this ethno-religious group Muslims in the Middle East, Afghanistan, as well as American Muslims, many of whom resided in this country for generations, became the object of resentment and often hate" (Livengood \& Stodolska, 2004, p. 183-184)

It must be mentioned that foreign policy in the Middle-East has also contributed to the lack of understanding towards Muslim governments. "When the United States is in conflict with an Arab country, negative opinions and views of Muslims tend to intensify" (Livengood \& Stodolska, 2004, p. 186). The situation in Iraq, Afghanistan, Pakistan, and Iran has contributed to the negative stereotype of Muslims in America and unfortunately other ethnic minorities who "look" Muslim. It is a "well documented phenomenon that not only Muslims or Arab Americans, but also members of other ethnic and racial groups experience a significant degree of discrimination in settings such as workplaces, public offices, housing, or even during causal encounters" (Livengood \& Stodolska, 2004, p. 186). The authors state, "out of the 25 interviewed individuals, 20 reported that either they or their close family members had been looked at in a strange manner, often with obvious disapproval, anger, and hostility" (Livengood \& Stodolska, 2004, p. 192). The study also mentioned how "Muslim women experienced cases of negative treatment in leisure activities and in their everyday lives with a much higher frequency than their male counterparts" (Livengood \& Stodolska, 2004, p. 193).

Mastrilli and Sardo-Brown (2002) focused on pre-service teachers' knowledge of Islam and measured their reaction to Islam after September 11, 2001. The researchers explain that the participants had limited knowledge about Islam. Specifically, Mastrilli and Sardo-Brown (2002) note in their discussion, "however, in terms of both inaccurate and knowledge and the lack of any knowledge concerning Islam, the survey responses do warrant concern" (p. 159). Future teachers may need to take courses in theology and learn how to be insightful of all religions. The next researcher focused on public opinion data on Muslims.

Panagopoulos (2006) researches the developments in public sentiment about Arab Muslim Americans and Islam in the age of the war on terror using available public opinion data in a quantitative retrospective study. According to Panagopoulos (2006), "the terrorist attacks against the United States on September 11, 2001, fueled widespread concern and speculation about mounting Islamphobic sentiment among Americans in response to the events" (p. 608). Data was gathered from the Roper Center's IPOLL database. Panagopoulos (2006) explains, "Since September $11^{\text {th }}$, survey data indicate majority of Americans consistently feel they do not understand the teachings of and beliefs within the religion of Islam" (p. 610). The results of the study show once again the lack of knowledge and the preconceived notions the general public has about Islam. According to Panagopoulos's (2006) study, data also showed: "That about 40 percent of Americans feel that the attacks on September 11, 2001 do represent the true teachings of Islam" (p. 611).

Kaifi (2009) completed a critical hermeneutic research study on the impact of 9/11 on Afghan-MuslimAmericans residing in the diverse San Francisco, Bay Area of California. The researcher had detailed conversations with a total of 10 participants. Kaifi (2009) stated that, "Post-9/11, all participants in this study either faced some form of discrimination or knew someone who had" and that "Afghan-Americans have been used as scapegoats post9/11 just like the Japanese-Americans and African-Americans have been used as scapegoats in the past" (p. 90). The literature review provides useful background information into the inquiry of diversity management of AfghanAmericans living in the post-9/11 era.

\section{THE PEOPLE OF AFGHANISTAN}

Afghanistan, a country with a history that is both bitter and sweet has become the center of attention throughout the world. Afghanistan's strategic location has enticed invaders to conquer the country time after time, and yet none have been successful. Ewans (2002) explains, "Although never colonized, Afghanistan is part of the 
colonial history of Tsarist Russia and British India" (p. 9). The past three decades of continuous war has left the country with a frail social, economical, and political infrastructure which has resulted in Afghans migrating to the West. As a matter of fact,

By May 1980, there were probably as many as 750,000 refugees in Pakistan and a further 100,000 in Iran. A year later, their numbers had grown to 1.7 million and 400,000 respectively. By 1984, the numbers had grown to 3.5 million and 1.5 million, more than one in three of the total population. Perhaps another 1.5- 2 million became internal refugees and fled from the countryside to the relative safety of towns. (Ewans, 2002, p. 158)

In the mid-20th century, Afghans began migrating to the U.S. for educational and professional purposes. The first wave of Afghan refugees arrived in the United States shortly after the former Soviet Union invaded Afghanistan in 1979 which resulted in a 10-year war with millions of casualties. As a result, most Afghans have spent at least two decades in America. Afghans have successfully built Islamic networks, opened up restaurants, and other small businesses. With the emergence of a generation of Afghan children raised and educated in the United States, the Afghan community has proven to be a dynamic force with high-standards and goals.

Afghans live a simple life that revolves around Islam. The foundation of Afghan culture and traditional life is Islam, because Islam is not only a religion but also a complete "way of life" (Livengood \& Stodolska, 2004, p. 185). Muslims are expected to practice their religion according to the time and space they live in. The Afghan identity consists of many components that are both commendable and recognizable. For example, most Afghans can speak two or three languages (Farsi, Pashto, and English), can read up to four languages (Farsi, Pashto, English, and Arabic), and are very honorable and hospitable (Kaifi, 2009, p. 9). According to Ewans (2002), "They [Afghans] will carry hospitality to embarrassing extremes, but are implacable enemies" (p. 9). Afghans who have relocated to America have been able to adapt to the American way of life while keep their own traditions (Kaifi, 2009, p. 9).

The first generation of Afghans who have grown up in America have been successful in pursuing their educational dreams. "Afghan leaders from all professions have started emerging. There are currently many AfghanAmerican medical doctors, engineers, attorneys, professors, police officers, and many who work in either the private or public sectors of the workforce" (Kaifi, 2009, p.10). Many Afghans have also proven to be strong leaders in their professions. A case in point is Dr. Mohammad "Mo" Qayoumi, the President of California State University, East Bay. As Afghans spend more time in America, more leaders will gradually emerge.

\section{DIVERSITY MANAGEMENT}

The topic of discrimination and minorities in the workforce post-9/11 is significant to research because "the research base on other minorities in management is quite small and is dominant by studies of Black men" (Wren, 1995, p. 169). Organizations should focus on the creation of an inclusive workplace (Mujtaba, 2010) and must be able to hire individuals from different backgrounds to be able to create a unique culture of valuing and embracing diversity. "Therefore, one challenge for American organizations is to assimilate a more diverse labor force into highstatus, high-skill management roles" (Wren, 1995, p. 168). Considering that each worker is different in respect to morals, values, and expectations, managers should provide a better understanding of their rules and policies along with diversity education for all their employees (Kaifi \& Mujtaba, 2009, p. 13). Organizations that have a diverse population are able to serve a wider range of customers. A case in point is how hospitals are trying to hire people of different backgrounds who can speak different languages to attract new patients who feel comfortable communicating in their native language. Currently, there are many elderly Afghan women in America who are desperately seeking female physicians who speak Pashto. Kaifi (2009) explains, "Organizational culture can easily influence an organization's success; therefore, a sound leader must be able to unite, empower, and motivate all employees" (p. 92). It is imperative for a senior manager to be able to think strategically and hire leaders from different backgrounds. As Wren points out, "Achieving diversity in management requires action. Continuous research will help ensure that effective action is taken" (Wren, 1995, p. 181).

Post-9/11, many Afghans have dealt with the glass ceiling phenomenon. Many believe that Afghans are affiliated with terrorism. "Ambiguity or lack of specific information about an individual contributes to bias against women and minorities because judgments are based on negative stereotypes of the groups as a whole" (Wren, 1995, 
p. 173). The negative stereotypes have resulted in minorities being discriminated against which has confirmed the glass ceiling concept. As a matter of fact, "There is considerable evidence that White women and people of color encounter a glass ceiling in management" (Wren, 1995, p. 169). Afghan-Americans are focused on becoming successful by obtaining advanced degrees and obtaining management positions. "Management and executive positions with professional and technical jobs, are among the fastest growing occupations between 1984 and 1995. However, these occupations include jobs not traditionally held by women and minorities, who comprise the new work force" (Wren, 1995, p. 168). Even with advanced degrees, minorities deal with discrimination and are at times looked down upon. "Discrimination occurs in part because of the belief by White men that women and people of color are less suited for management than White men" (Wren, 1995, p. 173). Interestingly enough, a study by Mujtaba and Kaifi (2009) illuminated how Afghans have higher scores on the relationship orientations which relates to higher levels of emotional intelligence and also to better job performance. "Therefore, managers and supervisors should feel comfortable in knowing that Afghan employees will complete the task at hand in a timely manner while maintaining a healthy relationship with their colleagues, peers, customers, and superiors" (Mujtaba \& Kaifi, 2009, p. 120).

\section{RESEARCH METHODOLOGY AND ANALYSIS}

Afghan-Americans who participated in this study completed a short survey with a total of twelve questions designed for the population. The survey instrument was distributed to 1,400 Afghan-Americans using Facebook as a social-networking instrument to encourage participation. A total of 502 surveys were completed by Afghans who live throughout the United States which yields a $36 \%$ response rate. All participants were informed that their participation was anonymous and voluntary. The research hypotheses for this study are as follows:

Hypothesis1: Male Afghans will have higher post-9/11 discrimination scores at work when compared to Afghan females.

Hypothesis2: Afghan respondents who have more education will have lower scores on changing their identity post-9/11.

Hypothesis3: Female Afghan will have higher post-9/11 discrimination scores in public when compared to Afghan males.

The responses of 502 Afghan-Americans demonstrate that they have been impacted by the events of 9/11 due to their ethnicity and religious beliefs. The survey asked about the experiences of each respondent, each respondent answered the questions based on a likert scale with 1 representing never and 5 representing always and the following are the results to the following three hypotheses:

Hypothesis 1 predicted that Afghan males would experience more discrimination at work post-9/11 when compared to Afghan females. This hypothesis, as presented in Table 1, is supported because the p-value of $(0.001)$ is less than the 0.05 level of significance and the t-value of 4.010 falls within the critical values. Further, $69 \%$ of the 280 Afghan male participants responded with a 4 or higher when responding to the question, Post-911 how often are you discriminated against in public? Approximately 50\% of the 222 Afghan females responded with a 4 or higher when responding to the same question. As such, this hypothesis is accepted.

\begin{tabular}{|l|c|}
\hline \multicolumn{2}{|c|}{ Table 1- Males vs. Females in regards to discrimination scores at work } \\
\hline Sample Size & 502 \\
\hline Males & 280 \\
\hline Females & 222 \\
\hline \multicolumn{2}{|c|}{ Two-Tailed Test } \\
\hline$t$-Test Statistic & 4.010 \\
\hline$p$-Value & 0.000 \\
\hline
\end{tabular}


Hypothesis 2 predicted that Afghan respondents who have more education will have lower scores on changing their identity post-9/11. This hypothesis, as presented in Table 2 , is not supported because the p-value of (0.623) is greater than the 0.05 level of significance and the $t$-value of -.492 does not fall within the critical values. As such, this hypothesis is rejected.

\begin{tabular}{|l|c|}
\hline \multicolumn{2}{|c|}{ Table 2- Education and the likelihood to change identity } \\
\hline Sample Size & 502 \\
\hline Males & 280 \\
\hline Females & 222 \\
\hline \multicolumn{2}{|c|}{ Education } \\
\hline High School Two-Tailed Test & 436 \\
\hline Bachelors & 66 \\
\hline \multicolumn{2}{|c|}{} \\
\hline$t$-Test Statistic & -0.492 \\
\hline$p$-Value & 0.623 \\
\hline
\end{tabular}

Hypothesis 3 predicted that Afghan females will have higher post-9/11 discrimination scores in public when compared to Afghan males. This hypothesis, as presented in Table 3, is supported because the p-value of (0.001) is less than the 0.05 level of significance and the t-value of -3.310 falls within the critical values. Further, $100 \%$ of the females reported a score of 3 or higher. Although males also scored high ( $90 \%)$ on experiencing discrimination in public, females reported higher scores than males.

\begin{tabular}{|l|c|}
\hline \multicolumn{2}{|c|}{ Table 3- Males vs. Females in regards to discrimination scores in the public } \\
\hline Sample Size & 502 \\
\hline Males & 280 \\
\hline Females & 222 \\
\hline \multicolumn{2}{|c|}{ Two-Tailed Test } \\
\hline$t$-Test Statistic & -3.310 \\
\hline$p$-Value & 0.001 \\
\hline
\end{tabular}

The participants in this study have most likely been discriminated against post-9/11 due to a lack of knowledge and understanding about Islam that is portrayed by the media and politicians. Although, conversations about Islam have become prevalent, the accuracy of what is said is questioned by many Muslims. With Islam being one of the fastest growing religions of the world, many believe that focusing on similarities as oppose to differences can help promote unity.

The research hypotheses for this study demonstrated that Afghan-American females and males and demonstrated that higher frequencies of discrimination post-9/11 in public while Afghan-American males reported higher frequencies of discrimination in the workplace. All of the participants in this study experienced some form of discrimination post-9/11, although in varying degrees (1-5). The post-9/11 era has been challenging for AfghanAmericans who are still not fully accepted in this society. Frank (2002) explains,

In times of fear, it is normal to look for someone to blame. Unfortunately, in the months after September $11^{\text {th }}$, some Americans looked to their Middle Eastern and Muslim neighbors. A gas station owner was shot dead because he was wearing a turban. There were other isolated attacks on Muslims. (p.120)

It is a fact that Islam does not prescribe or promote terrorism and is a religion based upon peace and righteousness. Even with all of the misinformation spreading about Islam, the religion is continuing to grow and as a result of the aftermath of $9 / 11$, more Muslims have become closer to their identity of being a Muslim which corroborates the study of Peek (2005) and Kaifi (2009). 


\section{IMPLICATIONS, LIMITATIONS, AND REFLECTIONS}

The implications of this study are that Afghan-Americans are experiencing more discriminatory practices both in public and in their workplace as a result of the unfortunate events of September 11, 2001. Afghans escaped Afghanistan and are now facing animosity simply because of their ethnicity and religious beliefs in the United States. September 11, 2001 was a horrific day that will never be forgotten and unfortunately, the aftermath has proven to be even more disappointing. It is important to keep in mind that all Muslims cannot be judged based upon the actions of a small minority. In comparison, Kaifi (2009) explains how in the case of Theodore Kaczynski, the Polish-American Unabomber who was responsible for a number of mail bombings, and unlike the AfghanAmericans, the Polish-Americans were not blamed for Theodore Kaczynski's foolish acts (p. 49). Thus, one is inclined to question why there is so much animosity towards Muslims.

The media is also responsible for portraying a tainted version of Islam. According to Esposito (1992), "Unfortunately, American policymakers, like the media, have too often proved surprisingly myopic, viewing the Muslim world and Islamic movements as a monolith and seeing them solely in terms of extremism and terrorism" (p. 5). The media can play an active role in salvaging the name of Islam in the West. Researchers believe that, "The second greatest danger to Islam is the incorrect, and often insensitive, reporting by the media" and further state "many of the major news reporters want to do the right thing, but they need to be educated about the truth of Islam" (Dirks \& Parlove, 2003, p. 96). It is important for Afghan-Americans to take initiative and show what being a Muslim actually means. This can be done by leading by example in all settings, focusing on unity and integrity, and by engaging in interfaith dialogues that focus on similarities as oppose to differences between religions. According to Ramadan (2004) "Muslims in the West bear an enormous responsibility, and it falls to them to commit themselves to building their future" (p. 224). Thus, diversity management becomes imperative in the workforce, educational settings, and in social settings.

There are several limitations to this study. The participants from this study represent a specific group of Afghan-Americans who are computer-savvy and in between the ages of 20 and 30 who use Facebook for social networking purposes. This most likely means that this sample of Afghan-Americans were either born in America or came to America at a very young age. Furthermore, a larger sample of participants from different age groups may have yielded different results. Lastly, there was only a 36\% response rate which can suggest that only those who had experience with what the survey was asking responded. Suggestions for further research include:

1) A ten year follow-up study on Afghan-Americans.

2) An investigation on other ethnic Muslim groups' post-9/11.

3) A post-9/11 assessment of Afghans who live in Canada or Germany.

\section{CONCLUSION}

In the months after September 11, 2001, there were hundreds of incidences involving violence, intimidation, and discrimination aimed at Muslims or people who looked like Muslims. "The aftermath of September 11, 2001 has been a gloomy experience for Muslims and many feel that on that day, the religion was hijacked" (Kaifi, 2008, p. 44). Barrett (2006) explains that "Opinion polls in 2004 showed that about a quarter of those responding held a negative stereotype of Muslims: that Muslims value life less than other people or teach their children to hate 'unbelievers.' Nearly half said that the U.S. government should limit Muslims' civil liberties" (p. 6). In our rapidly changing world, there is a critical need for mutual understanding and effective communication among all people. There is a need for a new, more encompassing "world view" as well as understanding and respecting all religions and cultures.

\section{AUTHOR INFORMATION}

Dr. Belal A. Kaifi will be a post-doctoral researcher at the University of Florida's Hough Graduate School of Business in 2010 where he will be researching Management and Marketing. He earned a doctoral degree from the University of San Francisco where he studied Organization and Leadership in the School of Education. Belal can be reached at: belalkaifi@yahoo.com. 
Wajma Aslami is a graduate student at Saint Mary's College of California where she is studying Counseling. Wajma is researching the counseling needs of Afghan women in the west. Wajma can be reached at: waslami@aol.com.

\section{REFERENCES}

1. Abdo, Geneive. (2006). Mecca and Main Street: Muslim life in America after 9/11. New York: Oxford University Press.

2. Barrett, Paul. (2006). American Islam: The struggle for the soul of a religion. New York: Farrar, Straus and Giroux.

3. Dirks, D. \& Parlove, S. (2003). Islam our choice. Beltsville, Maryland: Amana Publications.

4. Esposito, J. (1992). The Islamic threat: Myth or reality? New York: Oxford University Press.

5. $\quad$ Ewans, M. (2002). Afghanistan: A short history of its people and politics. NY: HarperCollins Publishers.

6. Frank, M. (2002). Understanding September 11th: Answering questions about the attacks on America. New York: Penguin Group.

7. Kaifi, B.A. (2008). Educating the Other: Impact of 9/11 on Afghan-Muslim Minorities. Sitara Magazine, 1(3), pp. $42-44$.

8. Kaifi, B.A. (2009). The impact of 9/11 of Afghan-American leaders. Bloomington, IN: Xlibris Publishers.

9. Kaifi, B.A. (2009). $21^{\text {st }}$ century leadership in healthcare. Pages 90-100. Chapter Twelve in the Pharmaceutical Technician Laboratory Manual by Sandeep Bansal. Jones and Bartlett Publications, Boston, Massachusetts.

10. Kaifi, B.A. (2009). A Critical Hermeneutic Approach to Understanding Experiences of Selected AfghanAmerican Leaders post-9/11 in the Bay Area. Doctoral Dissertation. University of San Francisco.

11. Kaifi, B.A., \& Mujtaba, B.G. (2009). Workforce discrimination: An inquiry on the perspectives of AfghanAmerican Professionals. Journal of Business Studies Quarterly, 1(1), pp. 1-15.

12. Kearney, R. (2003). Terror, Philosophy, and the Sublime: Some Philosophical Reflections on 11 September. Philosophy and Social Criticism, 29 (1), pp. 23-51.

13. Livengood, J. \& Stodolska, M. (2004). The effects of discrimination and constraints negotiation on leisure behavior of American Muslims in the post-September 11 America. Journal of Leisure Research, 36 (2), pp. 183-208.

14. Mastrilli, T. \& Sardo-Brown, D. (2002). Pre-service teachers' knowledge about Islam: A snapshot post September 11, 2001. Journal of Instructional Psychology, 29(3), pp. 156-161.

15. Mujtaba, B. G. (2010). Workplace Diversity Management: Challenges, Competencies and Strategies (2 $2^{\text {nd }}$ edition). ILEAD Academy Publications; Davie, Florida, United States.

16. Mujtaba, B. G., \& Kaifi, B. A. (2009). Afghan and American Professionals' Leadership Orientation toward Tasks and Relationships: Are there tendencies toward convergence or divergence? Fortune Journal of International Management, 5(1), pp. 107-125.

17. Peek, Lori. (2005). Becoming Muslim: The development of a religious identity. Sociology of Religion, 66 (3), pp. 215- 242.

18. Panagopoulos, Cost's. (2006). The polls- trends: Arab and Muslim Americans and Islam in the aftermath of September 11, 2001. Public Opinion Quarterly, 70(4), pp.608-624.

19. Ramadan, Tariq. (2004). Western Muslims and the future of Islam. New York: Oxford University Press.

20. Tatum, Beverly. (1997). Why are all of the Black Kids Sitting Together in the Cafeteria? NY: Basic Books.

21. Wagner, William. (2004). How Islam plans to change the world. Grand Rapids, MI: Kregel Publications.

22. Wren, J.T. (1995). The leader's companion: Insights on leadership through the ages. New York: Lexington Books. 
NOTES 